Royal Society, that Her Majesty's Consul-General at Christiania has reported that a considerable number of pits of "infusorial earth " containing 85 to 95 per cent. of silica are said to have been discovered in the neigbourhood of Stavanger.

Capital is being sought for the purpose of working the deposits, which are estimated to be capable of yielding 400,000 cubic metres of that rare product. It is affirmed that whilst the similar cleposits at Lüneburg, in Hanover, are mixed with sand and gravel, those now discovered are so pure in quality as to be available for most purposes merely after desiccation.

As this discovery may possibly have a scientific interest as well as a commercial value, I am directed to convey the above information to the Royal Society.

I am, Sir, your most obedient humble servant, T. V. LISTER.

The Secretary, Royal Society, Burlington House.

\section{The Electrical Condition of the Peak of Teneriffe.}

THE limited number of observations on atmospheric electricity which have been already made all point, with one exception, to a normal positive difference of potential between a point some few feet above the earth and the ground itself. The only notable exception to this law was found in some observations which were made on the Peak of Teneriffe about thirty years ago. Then it appeared that the condition of the Peak was constantly resinous or negative. These observations were, however, taken with a gold-leaf electrometer, and some doubt has been expressed as to whether the sign of the electricity was correctly obtained.

I therefore thought, when taking a short trip to Teneriffe, that it would be useful to examine this question by means of the improved electrical instruments now available.

Through the courtesy of the Meteorological Office I obtained the loan of a Thomson's portable electrometer, and, through the kindness of Mr. Whipple, received at Kew all necessary instruction in the use of the instrument, and special caution as to the possible difficulty of getting a good "earth" on sun-burnt lava. Any success the observations may have had is entirely due to his care and forethought.

I was only able to stay about a fortnight on the island, but the results obtained were so uniform that there can be no doubt as to their accuracy.

The height of the electrometer fuse was always about 5 feet 6 inches above the ground. At the Port of Orotava, at the base of the Peak, and about 50 feet above sea-level, the mean of eight sets of observations-each set usually consisting of six determinations-gave a potential of $\mathrm{I}_{3} 8$ volts. The highest was 193 , and the lowest 98 volts. These, and all 1 obtained in Teneriffe, were uniformly positive.

One day I took a skirmishing expedition to the rock of Gayga, a portion of the rim of the old crater, 7100 feet above the sea. On the way up, while on the pretty uniform slope of the mountain, at 3800 feet, the potential was only +99 volts, while on the rock itself, tension rose to 257 volts. The rock is a long sharp, narrow edge, perhaps half a mile long, with a precipitous cliff of 500 feet on one side. The rock was composed of dry lava, and I thought a little damp, but still the earth observations were not quite so accordant as usual.

A few days later, therefore, when starting for the top of the Peak, I took, as suggested by Mr. Whipple, an ordinary 66-foot iron surveyor's chain to be laid along the ground and connected with the instrument. The readings at different heights, on the way up, were as follows :-

At 5600 feet, on the slope of the mountain, III volts.

On the Cañadas, or rough flattish ground that forms the bottom of the old crater, at 5800 feet, 139 volts. The ground here was pumice and pumice dust, so I tried running ont the chain to see if the earth-readings would be altered. There was not however the slightest change, and to show the character of the observations five out of the six earth-readings gave the same number.

At the Estancia de los Ingleses, I0,500 feet, situated on the slope of the main peak, the potential fell to 118 volts. The sun was setting, and dew falling so fast that the top of the electrometer box was covered with wet. There could be no doubt then of obtaining a good earth.

On the top of the Peak, I 2,200 feet, the potential actually rose to no less than 549 volts. This was at 8 o'clock in the morning of October 24. The wind was blowing at the rate of about Io miles an hour from the north-east, while the dry and wet bulb thermometers marked $3 \mathrm{I}^{\circ}$ and $26^{\circ}$ respectively. There was a little white frost on the ground, and the earth-readlings, without the chain, were remarkably unifcrm, only differing by the II-Iooth of a turn of the screw.

The results of all the observations points unmistakably to the conclusion that during this month of October the electrical condition of the Peak of Teneriffe were the same as in every other part of the world. The potential was moderately positive at the same distance from the ground tven at considerable altitudes, but the tension rose enormously round a sharp point, aud a projcctins edge of rock.

It is well known that there are very few thunderstorms in Teneriffe, though one passed near us at Orotava without affect ing the indications of the electrometer. Would it not be interesting to measure the potential on the summit of a mountain like Kina Balu in Borneo, which is about the same height as the Peak of Teneriffe, but situated in the heart of the equatorial zone of the constant electrical discharge?

We had one day of very heavy rain, when possibly some negative indications might have been obtained; but I did not think it expedient to let the instrument get drenched.

But, besides obtaining these decisive electrical results, I was als ) very fortunate in some other observations during the short stay in Teneriffe.

We saw from the Estancia the shadow of the I'eak at sunset gradually creep along the land and surrounding sea, and then stand up in the air like another peak rising above the horizon. This is what is so often seen from Adam's Peak in Ceylon, and from Pike's Peak in Colorado.

Then our observations confirmed not only the important discovery made by P. Smyth, that cloud is not formed at the junction of a south-west current flowing over a north-east trade, but the even more important fact that there is no such thing as the supposed simple return current from the equator. At Teneriffe, as in every other part of the world I have ever visited, the general circulation of the air is on a complicated screw system, the practical effect of which is that as you ascend, the wind always comes more and more from your left hand as you stand with your back to the wind. You do not come abruptly to a south-west wind over a north-east trade, but pass successively as you rise from the surface from north-east through south to south-west, and then probably to west, or even north-west.

I also made some very important observations on the local formation of halo-forming sky, and got an excellent photograph of the genesis of a cirrus cloud from a moist current rising over the Peak, but space will not allow me to explain the results in this place.

2 I Chapel Street, London, November 7.

\section{"Toeing" and "Heeling" at Golf.}

I FEAR that "P. G. T.'s" reply to my letter on the above subject has left us very much in the same position as before. This is regrettable, as I hoped that further light would have been shed on this interesting mechanical problem. Before complying with the invitation to "think over the result of the impulsive rotation of the club-head," I considered it would be well to get some trustworthy observations on which to reason. With this object our professional, Mr. David Lowe, made twenty-seven tee shots with the driver, while I noted the effect. My instructions to him were, whether striking off the toe or the heel, to drive as truly as he could in the direction of an object selected for that purpose. The effects were as follows:- - When the ball went off the heel of the club, the ball in its flight curved to the right, even though its direction commenced obliquely to the left; to this there was no exception. The opposite curve, or to the left, with only one exception, was produced by hitting off the toe. Care was taken to ascertain in each case the point of impact of the ball on the club-face.

I now instructed him to try and curve the ball to the left, striking with the heel of the club, or to "toe it off the heel," in "P. G. T.'s" words. This feat he was unable to perform, and he gave it as his opinion that it could not be done.

Now for my explanation of "toeing" and "heeling " in reply to the invitation of "P. G. T."

Everyone who has played golf is aware that the ball when cleanly struck leaves a round mark upon the face of a new club of about five-eighths of an inch in diameter. This is the measure of the elastic distortion that takes place in the ball by the 